\title{
Obvervatório
}

\section{HACIA UNA DEFINICIÓN DE COMUNICACIÓN INSTITUCIONAL EN SITUACIONES DE CRISIS}

THE WAY TOWARDS A DEFINITION OF CORPORATE COMMUNICATION DURING A CRISIS

\author{
PARA UMA DEFINIÇÃO DE \\ COMUNICAÇÃO INSTITUCIONAL \\ EM SITUAÇÃO DE CRISE
}

\author{
Luis Gallardo Vera ${ }^{1}$ \\ Juan Pablo Micaletto Belda ${ }^{2,3}$
}

\section{RESUMEN}

El artículo asume como objeto de estudio la comunicación institucional en momentos de crisis. Como objetivo se marca sondear el establecimiento de una definición de comunicación institucional en situación de crisis que prescinda del reduccionismo periodista y que contemple la totalidad de aspectos de la comunicación corporativa. La metodología utilizada fue la de una investigación documental que realizó el análisis cualitativo de contenido de una selección teórica compuesta por una muestra elaborada siguiendo el criterio de elegir documentos (en formato de libros, capítulos de libros artículos, artículos, ponencias, etc.) que contengan enunciados validados científica y

\footnotetext{
${ }^{1}$ Formado em Filosofia e licenciado em Publicidade e Relações Públicas. Possui Mestrado em Gerenciamento de Comunicação, Especialista em Publicidade e Publicidade em Design Gráfico e Técnico de Publicidade. Ministério da Economia e Competitividade do espanhol na Seção de Comunicação do Departamento de Sociologia IV da Universidade Complutense de Madri (Métodos de Pesquisa e Teoria da Comunicação). E-mail: luigalla@ucm.es.

2 Doutor Interuniversitário em Comunicação das Universidades de Cádiz, Málaga, Huelva e Sevilha. Professor do Centro Universitário San Isidoro de Sevilha, vinculado à Universidade de Pablo de Olavide. E-mail: juanpablo.micalettobelda@mail.uca.es.

${ }^{3}$ Endereço de contato dos autores (por correio): Universidade Complutense de Madri. Av. Séneca, 2, 28040 Madrid, Espanha.
} 


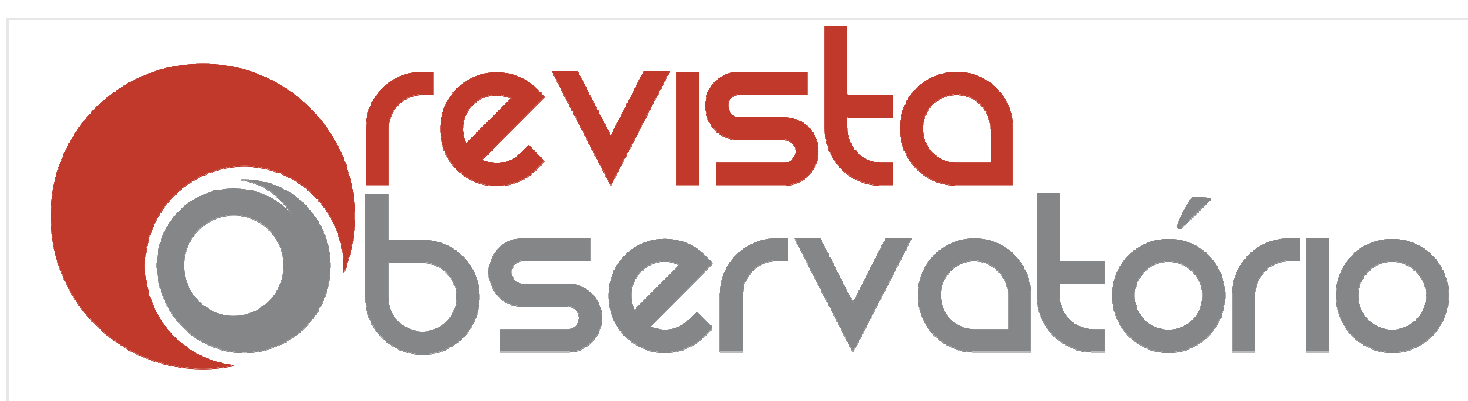

ISSN n² 2447-4266

Vol. 4, n. 1, Janeiro-Março. 2018

DOI: http://dx.doi.org/10.20873/uft.2447-4266.2018v4n1p437

académicamente y que versen sobre el objeto de estudio. La hipótesis que se confirmó consiste en la afirmación de que una definición completa de la comunicación institucional en situaciones de crisis debe ser holística y atender a las actitudes diversas y especiales de sus públicos estratégicos; siendo formulada tal definición teórica.

PALABRAS CLAVE: comunicación en crisis, comunicación institucional, comunicación institucional en crisis, público, estrategia.

\section{ABSTRACT}

The article defines as an object of study Corporate communication during a crisis. The aim would be to stablish a new definition for corporate communication during a crisis, ignoring journalist reductionism and adding the whole aspects of corporate communication. The methodology followed was a documentary research about qualitative analysis from theoretical selected content. As criteria, the samples selected contain just statements scientifically and academically certified and they deal with the object of study remarked above. The hypothesis confirmed after the research is based on the assertion that a complete definition of corporate communication during a period of crisis must be holistic and attend to the diverse and special attitudes of its strategic publics.

KEYWORDS: Communication in crisis, corporate communication, corporate communication in crisis.

\section{RESUMO}

O artigo assume como objeto de estudo a comunicação institucional em tempos de crise. O objetivo é investigar o estabelecimento de uma definição de comunicação institucional em uma situação de crise que dispensa o reducionismo jornalístico e contempla todos os aspectos da comunicação corporativa. A metodologia utilizada foi a de uma pesquisa documental com foco na análise qualitativa do conteúdo de uma seleção teórica composta por uma amostra preparada seguindo o critério de escolha de documentos (na 


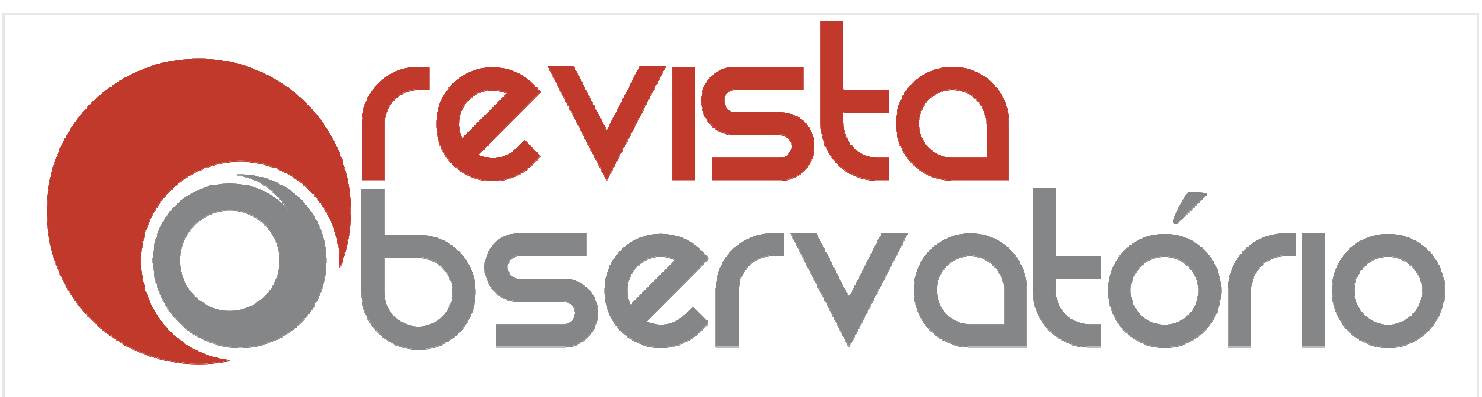

DOI: http://dx.doi.org/10.20873/uft.2447-4266.2018v4n1p437

forma de livros, capítulos de livros, artigos, papéis, etc.) que contém declarações científicas e acadêmicas validadas que se relacionam com o objeto de estudo. A hipótese que foi confirmada consiste na afirmação de que uma definição completa de comunicação institucional em situações de crise deve ser holística e abordar as atitudes diversas e especiais de seus públicos estratégicos, uma definição tão teórica que está sendo formulada.

PALAVRAS-CHAVE: Comunicação em crise; comunicação institucional; comunicação institucional em crise; publico; estratégia.

Recebido em: 31.03.2017. Aceito em: 01.12.2017. Publicado em: 01.01.2018. 


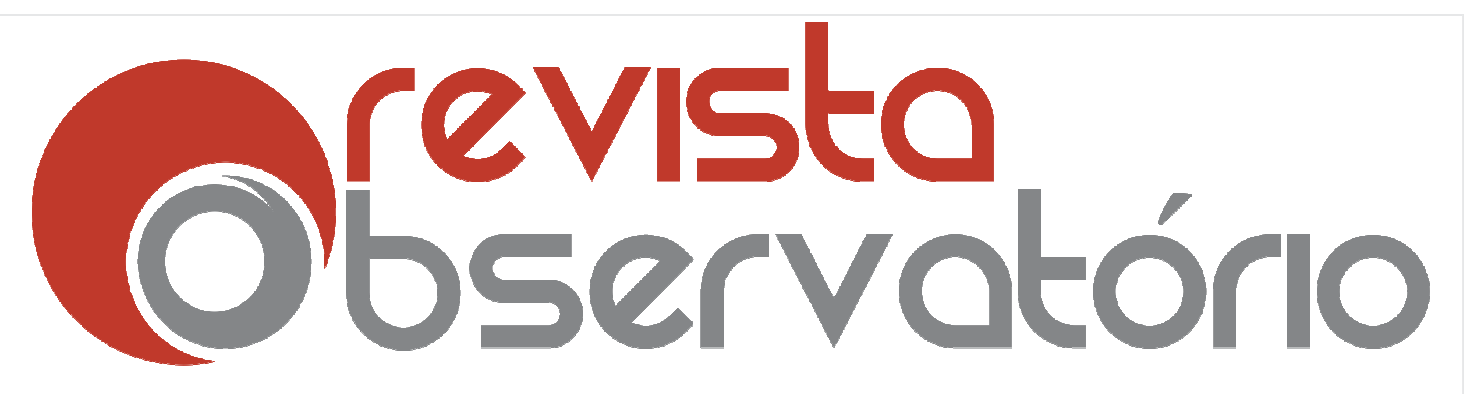

ISSN n² 2447-4266

Vol. 4, n. 1, Janeiro-Março. 2018

DOI: http://dx.doi.org/10.20873/uft.2447-4266.2018v4n1p437

\section{Introducción}

El concepto de crisis ha constituido un tema de argumentación para muchos estudiosos de la comunicación. Diversos autores, como García (2007), Fita (1999) o Burgueño (2014:136), han profundizado sobre este término y han establecido la relevancia que posee en el mundo actual. Todas las organizaciones (lucrativas o no lucrativas) están expuestas a que se originen situaciones de riesgo que afecten a su estabilidad (Castillo: 2010); máxime en un periodo de la historia marcado por la crisis financiera del año 2008, que ha desestabilizado a numerosos organismos.

En este escenario, el término "crisis" se ha extendido con facilidad. A pesar de la amplia notoriedad que tiene esta palabra entre la sociedad y de los cuantiosos estudios que existen sobre este vocablo, el concepto de comunicación institucional en crisis no ha sido cultivado en la misma intensidad.

Las organizaciones reaccionan ante sus públicos internos y externos comprometiendo su imagen (Piñuel: 1997). Estas instituciones, cuando están inmersas en una situación de crisis, comprometen especialmente su imagen y credibilidad ante sus grupos de interés $y$, en el caso de instituciones públicas, ante los ciudadanos a las que sirven. Por lo general, las definiciones de comunicación institucional en situación de crisis adolecen de una visión total de la comunicación y se reducen a una visión heredada del Periodismo que se centra, sobre todo, en la relación con los medios de comunicación Vidal y Hernández: (2013: 147).

Una gran parte de la literatura elaborada sobre gestión de crisis, como la difundida por diversos autores como Del Pulgar (1999), Saura (2005) o Villafañe (2004), entre otros, se centra principalmente en el ámbito empresarial. En la 


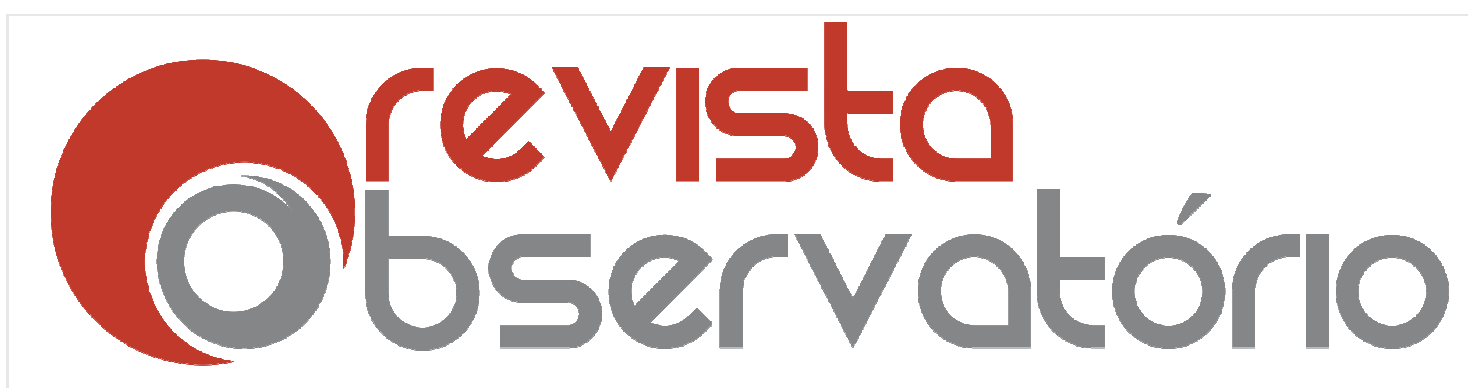

ISSN n² 2447-4266

Vol. 4, n. 1, Janeiro-Março. 2018

DOI: http://dx.doi.org/10.20873/uft.2447-4266.2018v4n1p437

comunicación institucional de crisis las variables a controlar son más numerosas y cuentan con una capacidad de impacto mayor.

Por esta razón, es de importancia constituir una definición que responda al problema estratégico y de imagen que implica una crisis sobre una institución.

El objetivo de la investigación presentada en este artículo consiste en sondear el establecimiento de una definición de comunicación institucional en situación de crisis que prescinda del reduccionismo periodista y que contemple la totalidad de aspectos de la comunicación corporativa. El artículo plantea la metodología utilizada en la investigación. En los resultados recoge el concepto de crisis, las características más relevantes de las situaciones de crisis y las definiciones más asentadas de comunicación institucional en crisis. Posteriormente realiza un recorrido por las nociones de los actos de habla, el carácter ubicuo del signo, el significado del signo, la comunicación estratégica y la actitud-predisposición hacia la organización por parte de los públicos estratégicos. Las conclusiones culminan con una propuesta fundamentada teóricamente de definición de comunicación institucional de crisis.

\section{Metodología}

El artículo aborda el objeto de estudio de la comunicación institucional en situaciones de crisis. El objetivo principal de la investigación fue sondear el establecimiento de una definición de comunicación institucional en situación de crisis que sea completa, de modo que prescinda de la reducción de la actividad comunicativa a la relación con los medios y que, por extensión, muestre si se da un déficit conceptual en este sentido en el entendimiento científico-académico de lo que es la comunicación institucional en situaciones de crisis. Se aplicó la lógica metodológica para la investigación teórica en Ciencias de la 


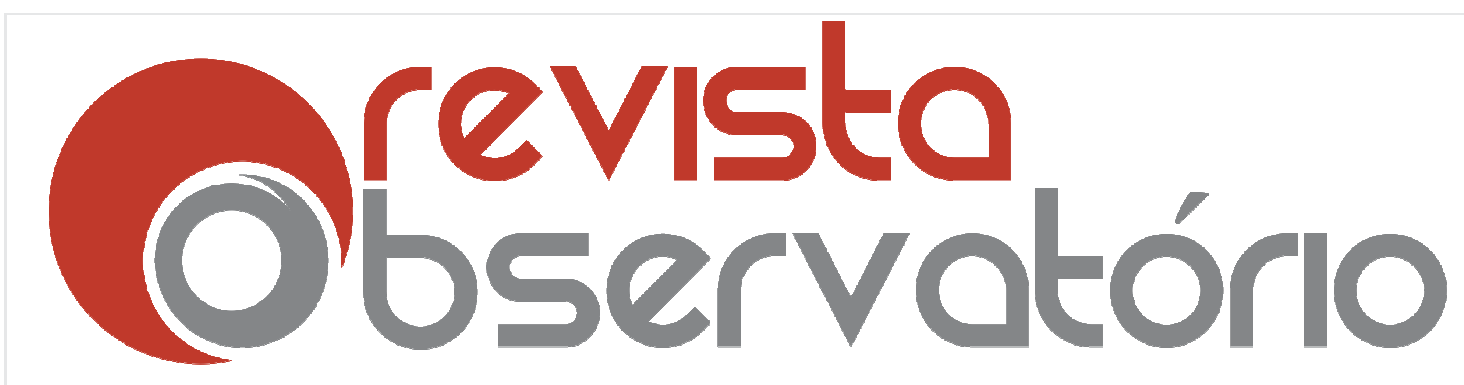

ISSN n² 2447-4266

Vol. 4, n. 1, Janeiro-Março. 2018

DOI: http://dx.doi.org/10.20873/uft.2447-4266.2018v4n1p437

Comunicación presentada por Gallardo (2016) en el I Congreso Internacional de Comunicación y Pensamiento. La hipótesis que se contrastó estriba en la afirmación de que una definición completa de la comunicación institucional en situaciones de crisis debe ser holística y atender a las actitudes diversas y especiales de sus públicos estratégicos.

Se utilizó una muestra documental cuyos contenidos giraron en torno al objeto de estudio y fueron analizados cualitativamente (Andréu: 1998). Esta muestra, de acuerdo a la metodología de investigación mencionada, fue producto de una selección teórica (Valles: 2002) y siguiendo el criterio de elegir documentos (en formato de libros, capítulos de libros artículos, artículos, ponencias, etc.) que contengan enunciados validados científica y académicamente y que versen sobre el objeto de estudio.

\section{Resultados}

\section{Las crisis institucionales}

Desde una perspectiva etimológica, Burgueño (2014: 136) recuerda que la palabra "crisis" deriva del sustantivo griego krísis (decisión) y del verbo kríno (decidir, separar, juzgar)", así como que sirve para designar el momento en que se produce un cambio importante en la sociedad, en las personas o en las organizaciones.

Piñuel explica sobre esta idea que:

La noción de crisis responde a un cambio repentino entre dos situaciones, cambio que pone en peligro la imagen y el equilibrio natural de una organización porque entre las dos situaciones (la situación anterior y la situación posterior a la crisis) se produce un acontecimiento súbito frente al cual una organización tiene que reaccionar comprometiendo su imagen y su equilibrio interno (como organización) y externo (como institución) ante sus públicos (Piñuel: 1997: 167). 


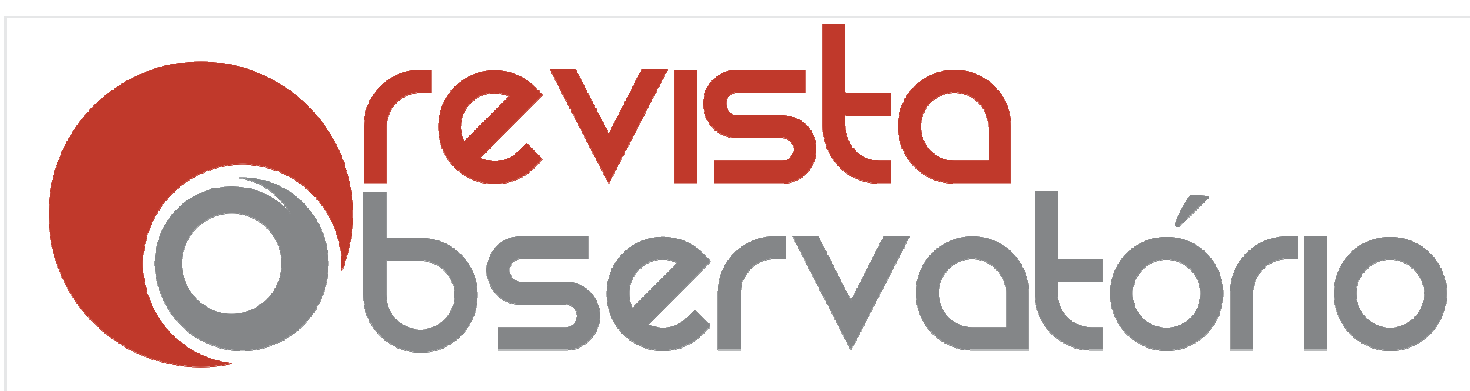

ISSN n² 2447-4266

Vol. 4, n. 1, Janeiro-Março. 2018

DOI: http://dx.doi.org/10.20873/uft.2447-4266.2018v4n1p437

Luecke apunta que:

Una crisis es un cambio repentino o paulatino, que provoca un problema urgente al que debe prestarse atención inmediatamente. Para una empresa una crisis es cualquier situación que tenga el potencial de causar un serio y repentino daño a sus empleados, a su reputación o a sus resultados finales (Luecke: 2005:12).

Cervera (2008:349) entiende que una crisis supone un hecho decisivo que afecta a la existencia o al futuro de la empresa. En tanto que las crisis son situaciones con trascendencia e importancia para los públicos de la organización, compromete la reputación, la capacidad y credibilidad de la misma. En esta misma línea, Wilcox, Cameron y Xifra (2010: 324) comprenden que una crisis es un acontecimiento extraordinario que afecta de forma adversa a la integridad de la organización y que genera, por lo tanto, una situación negativa que perjudica al producto, a la reputación, a la situación financiera de la organización y al público en general.

Desde el ámbito de actuación de las organizaciones, González Herrero define a la crisis como:

Una situación que amenaza los objetivos de la organización, altera la relación existente entre ésta y sus públicos, y precisa de una intervención extraordinaria de los responsables de la empresa para minimizar o evitar posibles consecuencias negativas. Dicha situación restringe, asimismo, el tiempo que los ejecutivos tienen para responder y suele producir niveles de estrés no presentes en circunstancias normales (González Herrero: 1998: 30).

Castillo (2010: 205), además, asevera que cada crisis posee una serie de características propias; "aunque no todas las crisis son iguales ni afectan de la idéntica manera a las organizaciones, sí que se exhiben unos elementos comunes a las situaciones de crisis". Según Castillo (2010: 205), estos elementos son:

- Afección a la imagen organizativa.

- Afectación al público interno. 


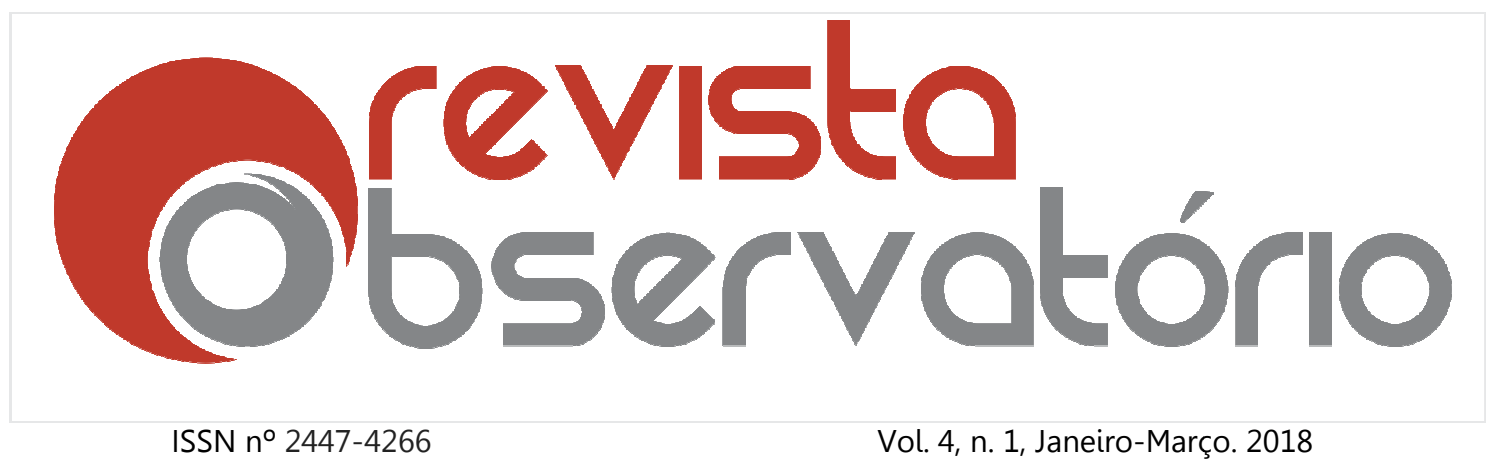

DOI: http://dx.doi.org/10.20873/uft.2447-4266.2018v4n1p437

○ Atención mediática.

- Buena imagen de las víctimas.

- Interés de los poderes públicos.

- Reputación social.

- Sorpresa.

- Urgencia.

Por otro lado, Cervera (2008:349) apunta las siguientes características comunes que están presentes en las crisis:

- Sorpresa.

- Información dispersa o insuficiente.

- Los acontecimientos suceden rápidamente.

- Los medios de comunicación suelen estar implicados.

- Sensación de pérdida de control, de ser arrastrado por las circunstancias.

En este sentido, Fita (1999: 125-126) recoge también algunas de las características expresadas por Cervera y Castillo: el factor sorpresa de las crisis, la unicidad de éstas y la situación de urgencia que generan. Fita anexa el siguiente aspecto:

Frente a esta avalancha de problemas, las organizaciones se ven más obligadas a reaccionar que a tomar la iniciativa y esto provoca la desestabilización en todos los procesos comunicativos, ya que hasta que no se ha producido el problema tenemos el control informativo sobre las situaciones normales, pero una crisis altera a todos los interlocutores que intervienen en el proceso de la defensa de la organización (Fita: 1999: 126).

\section{La comunicación institucional en crisis}

Gil (2013:28) manifiesta que el primer objetivo de la comunicación institucional, ante una ruptura del equilibrio, consiste en buscar un freno a la crisis que sirva para hacerse con el control de la información. Para que esta iniciativa sea eficaz, es necesario que se produzca a la mayor brevedad posible, 


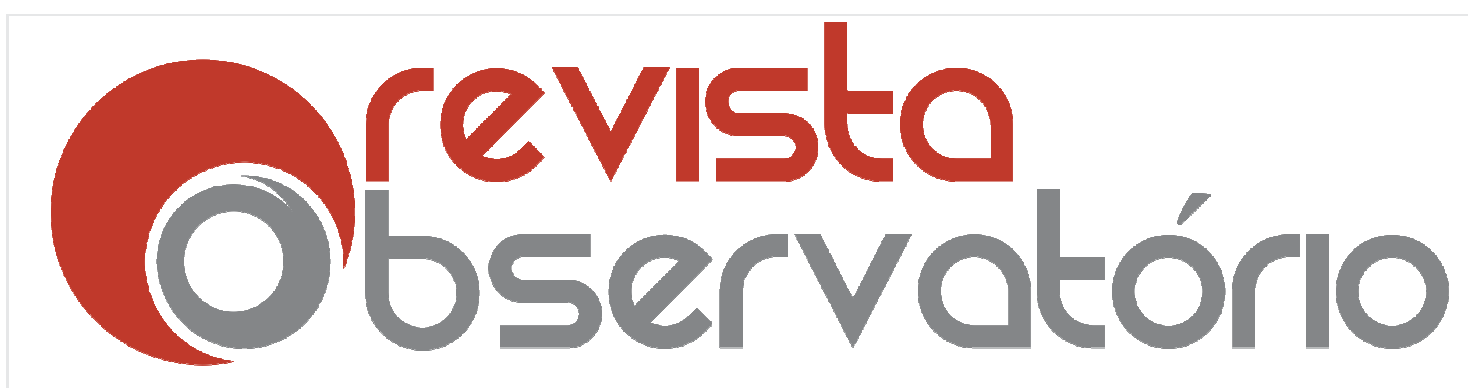

ISSN n² 2447-4266

Vol. 4, n. 1, Janeiro-Março. 2018

DOI: http://dx.doi.org/10.20873/uft.2447-4266.2018v4n1p437

a fin de reducir al máximo la pérdida de credibilidad e imagen de una institución ante sus públicos, ya sean medios de comunicación, líderes de opinión, clientes, consumidores, etc.

Martín (2006:32) llega a la conclusión de que en la comunicación institucional tiene una especial importancia conceptos como la identidad corporativa institucional (lo que se es) y la imagen corporativa/institucional (lo que se trasmite y percibe a través de la comunicación).

Para La Porte, la comunicación institucional es:

El tipo de comunicación realizada de modo organizado por una institución o sus representantes, y dirigida a las personas y grupos del entorno social en el que desarrolla su actividad. Tiene como objetivo establecer relaciones de calidad entre la institución y los públicos con quienes se relaciona, adquiriendo una notoriedad social e imagen pública adecuada a sus fines y actividades (La Porte: 2010: 492).

La comunicación institucional en crisis se fundamenta en la gestión de la imagen institucional. Por ende, la comunicación deberá defender las diferentes posturas del problema $y$, principalmente, la de una imagen puestas en tela de juicio (Fita: 1999: 141).

Para lograrlo, Burgueño (2014:47) indica que en este proceso la comunicación institucional debe buscar la mayor eficacia mediante la gestión de mensajes. Sotelo (2008:159) sugiere que la gestión de mensajes se efectúa en la administración del flujo comunicativo de las instituciones con sus públicos estratégicos. Tiene como meta descubrir y construir la identidad de la organización mediante el establecimiento de relaciones informativas, tanto internas y externas.

Burgueño (2014:47) entiende que hablar de comunicación institucional implica, normalmente, hacerlo sobre comunicación estratégica, cuyo planteamiento va dirigido a lograr una serie de objetivos previamente planificados. 


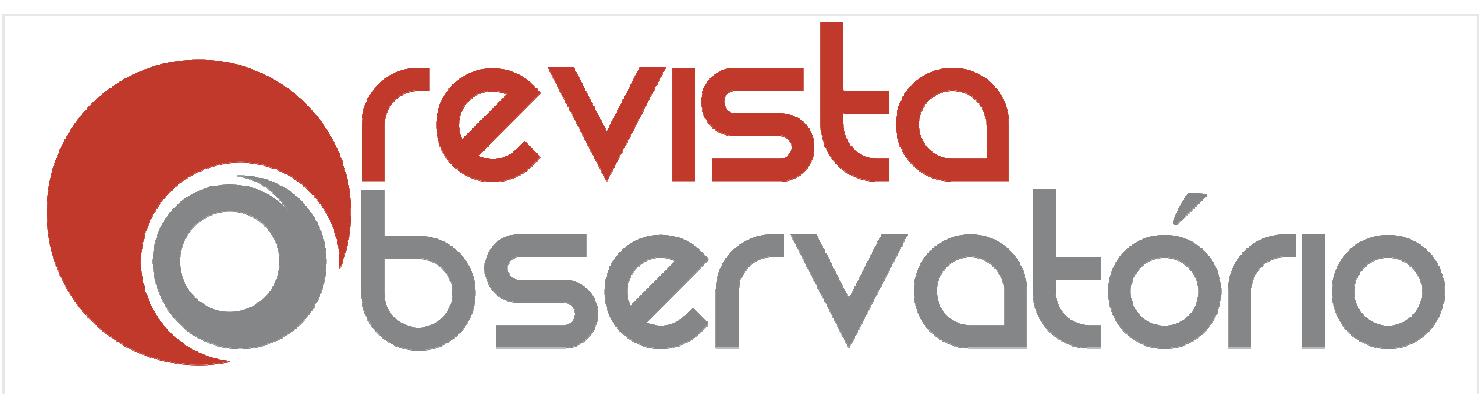

ISSN n² 2447-4266

Vol. 4, n. 1, Janeiro-Março. 2018

DOI: http://dx.doi.org/10.20873/uft.2447-4266.2018v4n1p437

\section{Los actos de habla}

La lingüística de Austin (1982) indica que todo acto comunicativo tiene tres dimensiones que se realizan al unísono. Un acto lingüístico realiza un acto locucionario (que consiste en decir algo), por el que la expresión lingüística que se emite en el acto contiene un aspecto fonético, uno gramatical y uno rético (compuesto por los elementos semánticos de la expresión). También realiza un acto ilocucionario, que consiste en hacer algo al decir algo (por ejemplo, mandar, recomendar, desear, etc.). Por último, realiza un acto perlocucionario, por el que la expresión emitida produce unos efectos determinados en los sentimientos, pensamientos y acciones del receptor. Esta última dimensión, según Austin (1982), está presente tanto en los actos de habla como en los actos comunicativos no verbales.

\section{El carácter ubicuo del signo}

Afirma Costa (1999: 118), desde el acervo de la comunicación corporativa, que todo existente significa. Geertz (1992), en la misma línea y desde la Antropología, concibe que los individuos están contextualizados semánticamente en el universo cultural. Según Geertz (1992), los individuos están atravesados por tramas de significación en un hábitat cultural. Estas tramas de significación contienen estructuras que obedecen a distintos ámbitos sociales y que influyen sobre los individuos.

El carácter ubicuo del signo enraíza en la esencia cultural del hombre (Pérez, 1995). En la posición holística de Geertz se sitúa Heidegger (1997: 8496), quien asegura que el mundo del hombre está compuesto de entes que son signos. Las posiciones de Geertz y de Heidegger son coherentes con la división peirciana de los signos. Peirce (1986) concibió tres clases de signos 


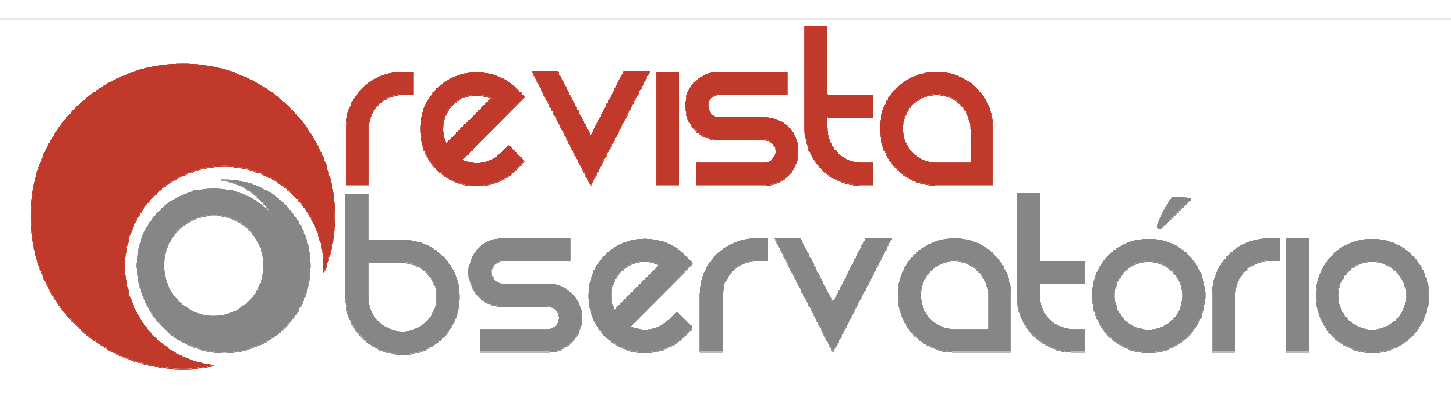

ISSN n² 2447-4266

Vol. 4, n. 1, Janeiro-Março. 2018

DOI: http://dx.doi.org/10.20873/uft.2447-4266.2018v4n1p437

considerando su naturaleza: cualisignos, sinsignos y legisignos. Los cualisignos son cualidades, como el color y la forma de un objeto. Los sinsignos son objetos individuales o eventos, como una casa o una pelea concretas. Los legisignos son signos convencionales y universales, como las unidades del lenguaje escrito, una norma o un concepto científico.

La semiótica de Peirce influyó en las investigaciones de la Escuela de Palo Alto y, en concreto, de Bateson (Lucerga, 2003, 2005). Esta Escuela investigó desde el paradigma del modelo de comunicación de Weiner. Dentro de esta Escuela, Watzlavick asentó la idea de la comunicación como un proceso social constante que comprende múltiples niveles sígnicos en el axioma "todo comunica" (Mattelart, 1995). En el plano de la comunicación corporativa este axioma ha sido interpretado entendiendo que "todas las acciones y comportamientos de una organización tienen una dimensión comunicativa, es decir, hablan de la entidad" (Capriotti, 2009: 29).

Esta visión holístico-comunicativa y multisígnica entronca con la visión de las sociedades de la información expuesta por Braudillard (2000), quien adiciona a la caracterización de las sociedades de la información la omnipresencia del signo como factor fundamental de reproducción social. Verón (1993) mostró cómo se genera la semiosis, por la que los signos instituyen el sentido de la realidad articulándose en discursos. Así las sociedades de la información se estructuran y actualizan modeladas por discursos, signos y códigos, de modo que acontece una operativización general del significante que canaliza la producción de sentido y que utiliza el poder productor de los signos.

Los signos contienen distintas informaciones (Vera, 2006) e implican distintos mensajes que se comunican por distintos canales. Capriotti (2009) distingue tres niveles de canales de información atendiendo a las fuentes en la 


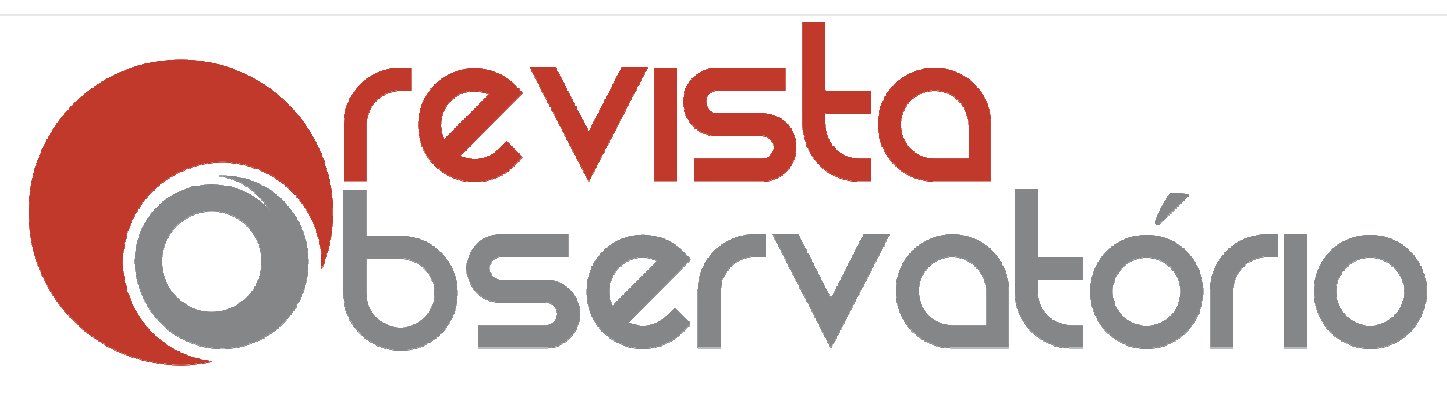

ISSN n² 2447-4266

Vol. 4, n. 1, Janeiro-Março. 2018

DOI: http://dx.doi.org/10.20873/uft.2447-4266.2018v4n1p437

comunicación de una organización con sus públicos, que suponen vías de relación para la recepción de los mensajes: comunicación masiva (relación medios de comunicación-individuo), relaciones interpersonales (relaciones individuo-individuo) y experiencia directa (relación del individuo consigo mismo). Las dos primeras proveen información socialmente mediada, mientras que la tercera genera información directamente experimentada. Los signos vehiculan por los sistemas de representación, emisión y recepción sensorial que postula la PNL: canales visuales, auditivos o kinestésicos (Cudicio, 1991; Romo, 2006); entendiendo por canal a todo medio material de transmisión de signos y por mensaje a todo signo en tanto comunicado (Jakobson, 1986), con un contenido informativo y con una forma expresiva (Hjelmslev, 1971).

\section{El significado del signo}

Aparte de la aportación de Peirce, la Semiótica contemporánea tiene como referente principal a Saussure (Redondo, 2006: x). Entre los conceptos que Saussure desarrolló dentro de la semiótica está el del carácter bidimensional del signo. Para Saussure (1945; Magariños, 1983) el signo es una entidad psíquica de dos dimensiones. El significante es la imagen que produce el aspecto material del signo, el aspecto perceptual y sensitivo del signo, la expresión del signo. El significado es el concepto abstracto que produce el significante del signo y que está referido a un objeto real. La concepción bidimensional de Saussure, aunque originariamente fue pensada para los signos lingüísticos, es aplicable, mutatis mutandis, a los signos no lingüísticos (Magariños, 1983: 44 y ss.).

El significado de un signo es, como dice Saussure (1945), un concepto abstracto, que produce el significante del signo y que está referido a un objeto real; sin embargo, la noción del significado de Saussure es una noción 


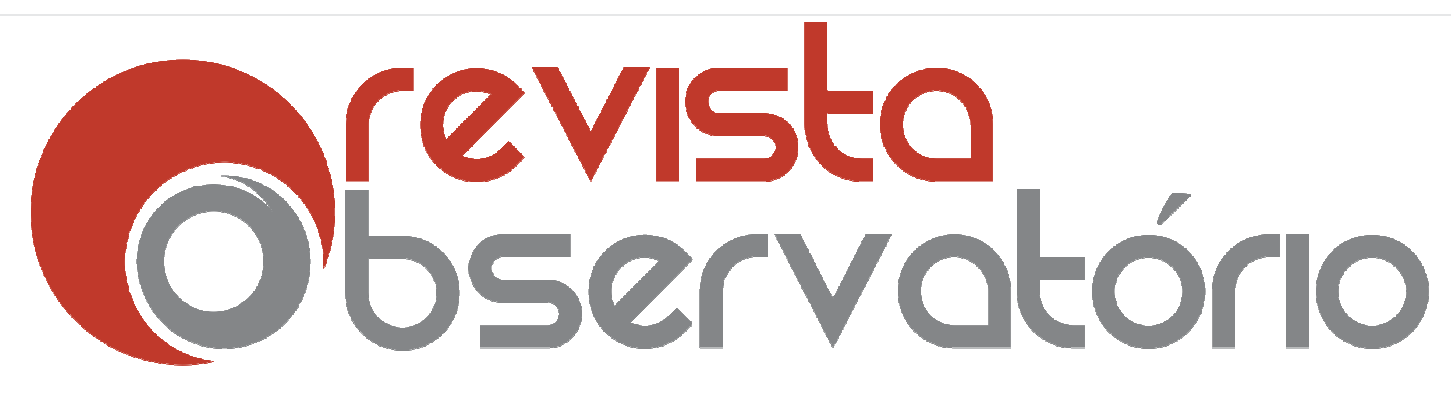

ISSN n² 2447-4266

Vol. 4, n. 1, Janeiro-Março. 2018

DOI: http://dx.doi.org/10.20873/uft.2447-4266.2018v4n1p437

intelectualista del significado de los signos, que sólo atiende al concepto abstracto que el signo genera en la mente del sujeto del signo. Peirce (Atencia, 2003: 9-11), en cambio, postula que el efecto mental que producen los signos se desglosa en tres efectos significativos en los sujetos de los signos: lógico, emocional y energético. Peirce comprendió todo signo estructurado comunicativamente en un sujeto emisor y en un sujeto interpretante (Redondo, 2006: 111-112). La concepción dialógica y efectista de Peirce es consonante con la noción de acto perlocucionario de Austin (1982). Para Austin un acto sígnicocomunicativo es un acto perlocucionario, en tanto que produce efectos en los pensamientos, sentimientos y acciones de los receptores de los signos.

El efecto mental lógico de los signos incluiría el significado saussuriano, empero, un signo evoca tanto un concepto abstracto como un concepto individual (Pierce, 1986). En términos humeanos (Hume, 1959), los conceptos individuales son imágenes-percepciones simples, y los conceptos abstractos, imágenes-percepciones compuestas. En este sentido, los significantes impresionan a los sujetos receptores y producen en ellos ideas-imágenes simples y compuestas.

El efecto mental emocional de los signos correspondería al carácter existencial del signo que postula Heidegger en Ser y Tiempo (1997: 84-86, 137163). Heidegger conceptúa el signo dentro de su ontología existencial. El signo es cooriginario con el comprender y con la disposición afectiva. Muestra Heidegger que las significaciones de los signos procuran en los individuos efectos emocionales que implican comprensiones del mundo. Los signos tienen una remisión existencial que consiste en dotar a los individuos de una visión panorámica del mundo y de una orientación en él. Esta visión y esta orientación se obtienen mediante las comprensiones del mundo que provocan las significaciones de los signos. Sobre esta base los individuos interpretan al 


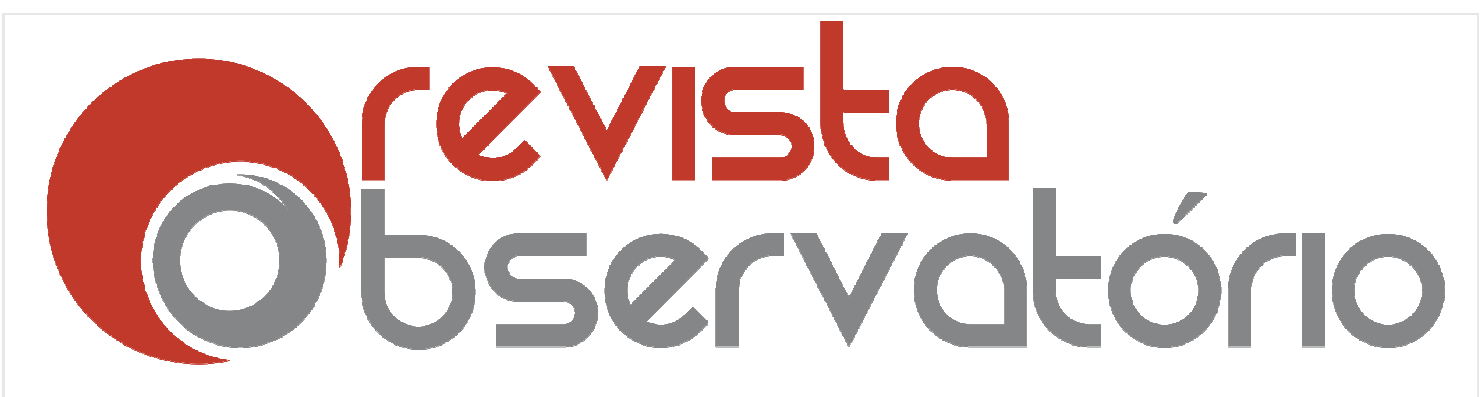

ISSN n² 2447-4266

Vol. 4, n. 1, Janeiro-Março. 2018

DOI: http://dx.doi.org/10.20873/uft.2447-4266.2018v4n1p437

mundo apropiándose de estas comprensiones y así comprenden el mundo más hondamente. Las interpretaciones comprensoras suponen proyecciones de los individuos hacia sus posibilidades existenciales. Se da una articulación existencial de los sentidos.

El efecto mental energético de los signos correspondería a la teoría conductista del significado. Esta teoría afirma que los significados son estímulos para ocasionar conductas. Representantes de esta teoría fueron Watson, Paulov y Skinner (Pinillos, 1971: 103-111). Bloomfield (1968) insertó a la relación significado-estímulo-conducta en el proceso de comunicación.

Desde el punto de vista de la medición de los efectos comunicativos generados por las organizaciones (Wimmer \& Dominick, 1996), y en consonancia con los tres efectos sígnicos discernidos por Peirce, los efectos comunicativos de los signos son: cognitivos, emotivos y conductuales.

En los modelos de comunicación la tradición efectista de la comunicación tiene su referente en el modelo de Lasswell (1948; Mattelart, 1995: 30-31). Desde el modelo de comunicación de Lasswell, en el proceso comunicativo un emisor (quién) comunica a una audiencia (a quién) un mensaje-contenido informativo (qué) utilizando distintos canales-medios (por qué canal) y con el fin de obtener efectos (con qué efecto).

\section{La comunicación estratégica}

Los nexos y distancias entre las comunicaciones de marketing y las relaciones públicas han sido tema de una intensa y extensa discusión (Castillo, 2010: 52 y ss.). Ambas clases de comunicación pretenden, en última instancia, conseguir la misión de la organización. Mientras la comunicación comercial (comunicación de marketing) pretende conseguir un comportamiento de compra en el público objetivo consumidor-cliente, las relaciones públicas 


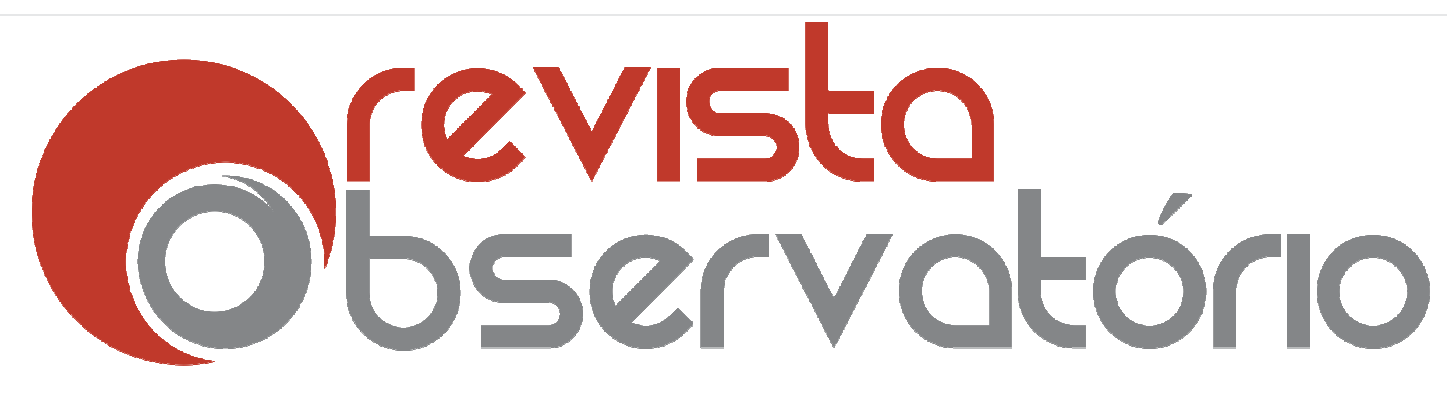

ISSN n² 2447-4266

Vol. 4, n. 1, Janeiro-Março. 2018

DOI: http://dx.doi.org/10.20873/uft.2447-4266.2018v4n1p437

(comunicación institucional) pretenden conseguir en el público objetivo comercial y en el resto de públicos clave de la organización un comportamiento de apoyo a todas las actividades de la organización como tal (incluida la comercial).

Existe un amplio debate sobre el concepto de 'comunicación corporativa' (Herranz, 2007). Básicamente, la comunicación corporativa, tomando como base las afirmaciones de Van Riel (1997) y de Grunig y Hunt (2000), se divide en comunicaciones de marketing y en relaciones públicas entre la organización y sus públicos internos y externos.

La comunicación corporativa engloba a todos los signos de la organización, a todos los significados que emite y son susceptibles de ser gestionados (Costa, 2009; Capriotti, 2009; Minguez, 2000; Véliz, 2006).

La comunicación corporativa supone el uso del poder simbólico e instaura y fortalece relaciones de poder. Las fuerzas que se activan comunicativamente aplican estrategias que las organizaciones utilizan a fin de conseguir sus objetivos. Estas estrategias de comunicación se conforman mediante dos elementos: emisión discursiva e introyección discursiva. Los discursos suponen prácticas discursivas. De este modo, los discursos y las prácticas que los sostienen y crean (emisoras e interiorizadoras) se encadenan en sucesivas capas de emisión-recepción-emisión (Beltrán: 2007). Las prácticas discursivas implican producción de discursos y conductas interiorizadoras de contenidos discursivos producidos, de modo que los discursos engloban prácticas productoras y prácticas receptoras. La producción de un discurso por un emisor presupone la asunción por parte del emisor de discursos que generan la producción y la emisión de ese discurso. Además, los destinatarios del discurso generado lo interiorizan y el discurso resulta efectos cognitivos, afectivos y conductuales. Estos efectos se sintetizan en prácticas discursivas 


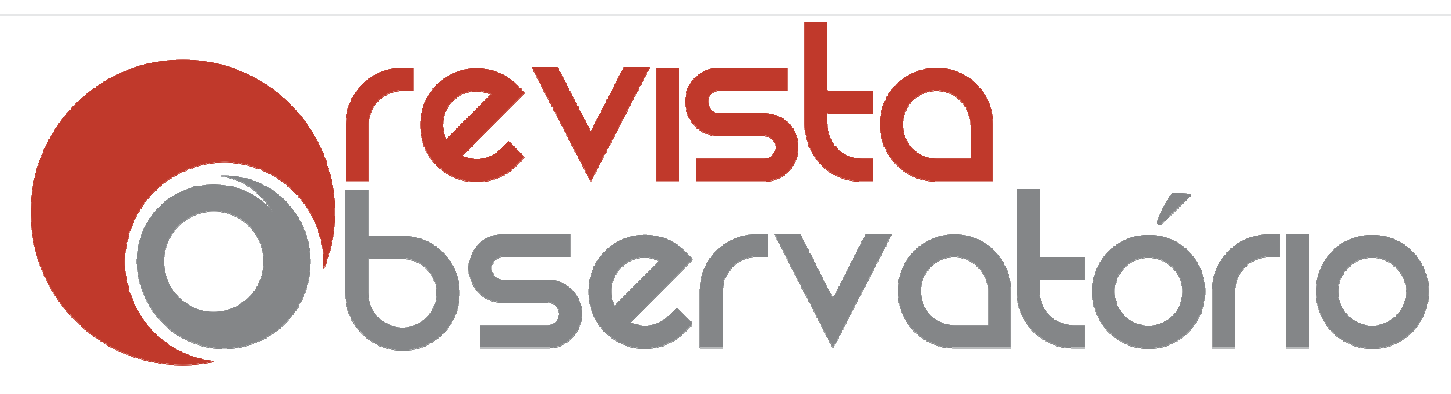

ISSN n² 2447-4266

Vol. 4, n. 1, Janeiro-Março. 2018

DOI: http://dx.doi.org/10.20873/uft.2447-4266.2018v4n1p437

interiorizadoras que son prácticas productoras de futuros discursos. Los receptores interiorizan y emiten discursos. Los emisores interiorizan y reciben discursos. Tanto en la emisión como en la recepción de discursos el individuo se encuentra atravesado socialmente (Gadamer: 2001). De esta forma, se componen cadenas temporales de prácticas discursivas. Por tanto, las prácticas discursivas son prácticas emisoras de discursos y prácticas interiorizadoras de discursos.

Los discursos constituyen entidades dinámicas, semánticas, pragmáticas y perlocutivas cuyos contenidos se refieren a la realidad externa e interna de los individuos. La realidad está instituida en el ámbito de lo simbólico y provista inherentemente de una dimensión semántica, social y pragmática. Los discursos se refieren a contextos de interacción y comprenden procesos de producción, emisión, difusión y recepción. No se trata, por consiguiente, de escindir ontológicamente el plano de los significados del plano de los referentes o del plano de las condiciones de producción del sentido, a modo de Foucault (Buenfil, 1996), quien distingue prácticas discursivas de prácticas no discursivas y establece una delimitación entre las condiciones de producción comunicativa, los mensajes producidos, los actos que resultan y las referencias de los mensajes. Se trata de contemplar comunicativamente todos los factores envueltos en la construcción de sujetos, factores que son insoslayables para la creación y pervivencia de los sentidos individuales y sociales.

El concepto de "práctica discursiva" explica el modo de producción de la realidad multisígnica y discursiva. El concepto de "práctica discursiva" tiene su origen en la obra de Foucault (Klaus, 2002; Buenfil, 1996) y ha sido perfilado por Laclau y por Van Dijk, entre otros. Las prácticas discursivas constituyen puntos nodales de los discursos. Las prácticas discursivas son receptoras de discursos y, al mismo tiempo, emisoras de discursos: reciben, practican e interiorizan 


\section{Observatório}

ISSN n² 2447-4266

Vol. 4, n. 1, Janeiro-Março. 2018

DOI: http://dx.doi.org/10.20873/uft.2447-4266.2018v4n1p437

significantes y significados y refuerzan, producen y emiten significantes y significados. Como en Saussure (Magariños, 1983), los distintos niveles prácticodiscursivos se encadenan entre sí. Una práctica discursiva es, por ende, una práctica significada y una práctica significante.

La comunicación en su aspecto relacional es un modo de poder (Matilla, 2008: 38). El poder es la capacidad para actuar interviniendo en el decurso de los acontecimientos y en sus resultados, de cara a la consecución de los propósitos e intereses individuales o colectivos (Thompson, 1997: 29). Esta capacidad se materializa en los recursos disponibles (medios) para lograr objetivos e intereses de un modo efectivo. De ahí que mediante la acumulación de diversos recursos los individuos y los colectivos puedan aumentar su poder.

Thompson (1997) distingue cuatro tipos de poder. El poder económico procede de la actividad humana laboral, destinada a abastecer de medios de subsistencia por medio de la extracción de materias primas y de su transformación en bienes, que pueden consumirse e intercambiarse en un mercado. El poder político procede de la actividad de coordinar a los individuos y de regular los patrones de su interacción. Todas las organizaciones implican un cierto grado de coordinación, regulación y poder político. A esta acepción hay que anexar el sentido originario de polis. el poder político es la gestión de los recursos para resolver los asuntos públicos y colectivos. El poder coercitivo supone el uso o la amenaza de utilizar la fuerza física para someter o vencer a un oponente. Por último, el poder simbólico proviene de la actividad productora, transmisora y receptora de signos.

El poder simbólico envuelve a las otras formas de poder. Lewandowski (1982: 262) define a la comunicación persuasiva como la "manipulación de signos con la intención de desatar una determinada conducta en la persona a la que nos dirigimos". En este sentido, la comunicación persuasiva supera la 


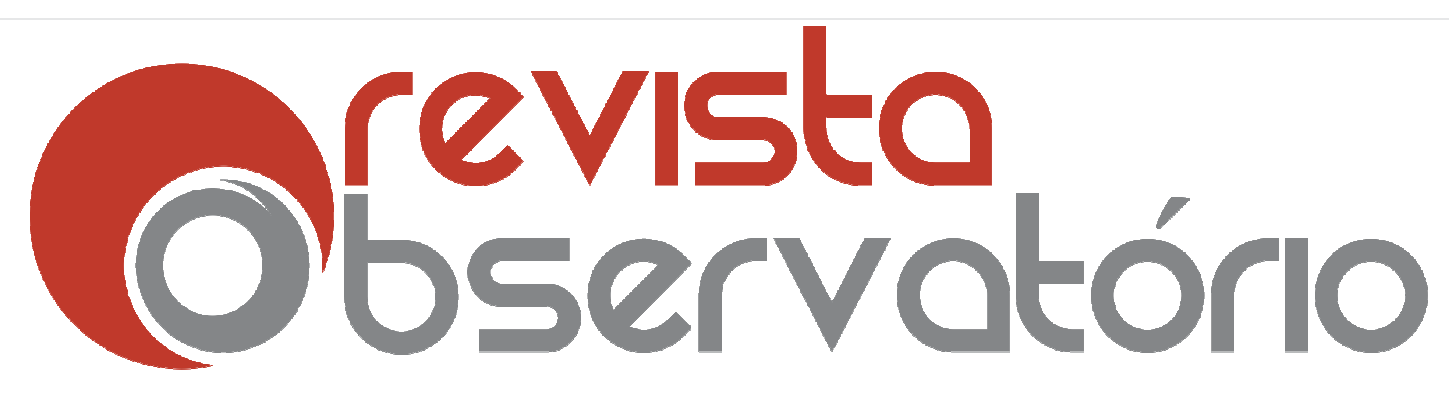

ISSN n² 2447-4266

Vol. 4, n. 1, Janeiro-Março. 2018

DOI: http://dx.doi.org/10.20873/uft.2447-4266.2018v4n1p437

distinción lingüístico/no lingüístico y entiende a todo ente como un signo y, por tanto, a todo ente como un recurso de poder simbólico.

Además, el poder simbólico se instituye por prácticas discursivas. Como apunta Santillán (2001), las relaciones de poder no pueden disociarse ni funcionar sin una producción, una acumulación, una circulación y un funcionamiento del discurso. Foucault ha estudiado extensamente las prácticas discursivas que construyen el poder. Para Foucault el poder no radica sólo "en las cosas materiales ni en la fuerza física ni en la psicológica como formas de control y dominación sobre los individuos" (Ortiz, 2006: 11). Funciona y se despliega mediante una organización reticular, lo que significa que "transita transversalmente sin permanecer quieto en los individuos" (Foucault, 1991: 144).

El poder y, por extensión, el poder simbólico consisten en acciones sobre acciones, en un conglomerado de fuerzas que actúa con relación a otro conglomerado de fuerzas con la intención de dominarlas. Estas relaciones de fuerza adoptan la forma de estrategias. Los efectos de dominación son consecuencias de dispositivos y tácticas, que se desarrollan y que abarcan una red de interrelaciones de tensión multivariable y mutua y que operan como formas de producción de poder (Foucault, 2005).

La comunicación es estratégica, si se gestiona con criterios estratégicos la capacidad que posee la comunicación de alterar la percepción de la realidad y de movilizar a la acción (Matilla, 2008). En esta línea, la comunicación estratégica encauza el poder simbólico incidiendo en los resultados de la interacción social y en la consecución de objetivos.

Arceo (1999) concibió la comunicación estratégica como la gestión de la comunicación persuasiva para obtener objetivos. Salas (2001), por otro lado, defendió la sustitución de la expresión "comunicación persuasiva" por la de 


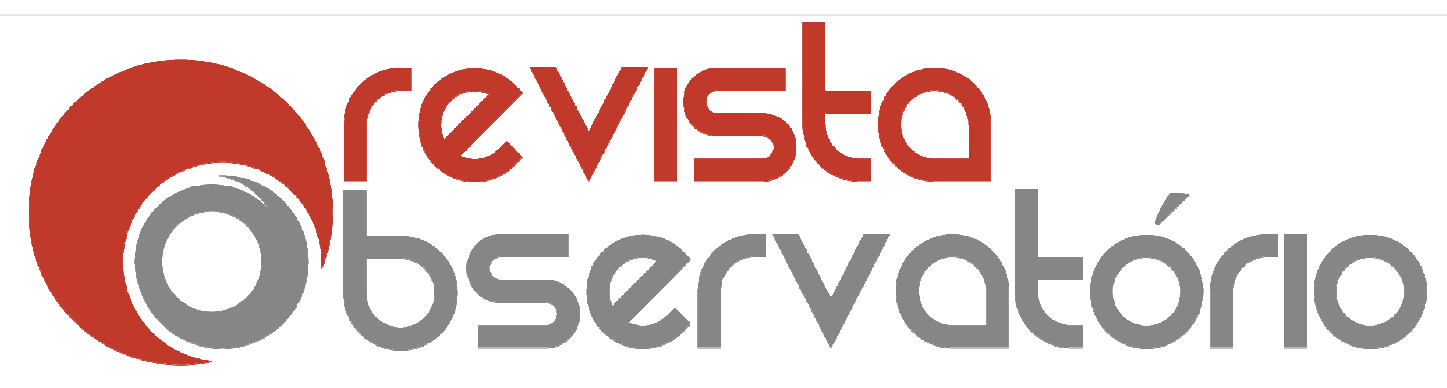

ISSN n² 2447-4266

Vol. 4, n. 1, Janeiro-Março. 2018

DOI: http://dx.doi.org/10.20873/uft.2447-4266.2018v4n1p437

"comunicación estratégica". Si bien la expresión más adecuada es "comunicación estratégica", es necesario separar el fenómeno de la persuasión comunicativa del fenómeno de la ideación y aplicación de estrategias. En el fenómeno de la persuasión comunicativa un sujeto recibe un mensaje que cambia sus ideas y conductas. En el fenómeno de la ideación y aplicación de estrategias un sujeto utiliza la persuasión comunicativa como recurso para obtener determinados fines.

\section{La actitud-predisposición hacia la organización}

En los contextos de crisis las instituciones ven especialmente comprometida su imagen (Capriotti: 2009) y, por tanto, la actitud de apoyo de los públicos estratégicos hacia ellas. Para gestionar la imagen corporativa, entre otras técnicas, se utiliza la técnica de la segmentación por mapa de públicos (Costa: 2009), que delimita a los públicos según su relevancia para conseguir los objetivos y la misión de la organización. El marketing social contempla una segmentación que se refiere a contextos sociales en los que los públicos objetivo no están predispuestos a practicar comportamientos que se pretende que realicen. Esta segmentación se adecua a modelos de cambio de comportamiento contrastados (Gallardo, 2014) y atiende a las distintas problemáticas actitudinales de los públicos estratégicos, según niveles de demanda y de intensidad de la actitud de los públicos estratégicos hacia la organización.

Mientras que los mercados a los que se orienta el marketing comercial son mercados con una demanda positiva (los consumidores demandan el producto), los mercados a los que se orienta el marketing social son mercados con una demanda negativa (los consumidores no demandan el producto) (Leal, 2004: 42). Como afirman Díaz y Miquel, "el principal problema con que se 


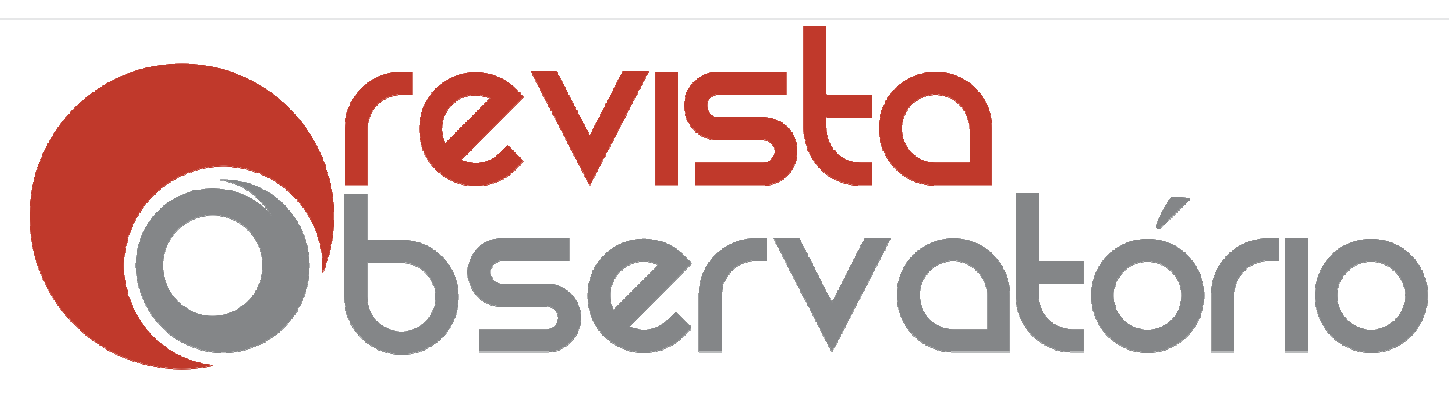

ISSN n² 2447-4266

Vol. 4, n. 1, Janeiro-Março. 2018

DOI: http://dx.doi.org/10.20873/uft.2447-4266.2018v4n1p437

encuentra el especialista en marketing social es que, generalmente, los "consumidores" que constituyen su mercado meta son aquellos que están más fuertemente predispuestos en contra del producto" (Miquel et al., 1990: 101).

Aunque el marketing comercial considera los modelos de cambio y de formación de actitudes, en el marketing social esta perspectiva es más acusada que en el marketing comercial, ya que, como indican Díaz y Miquel, "mientras en el marketing comercial existe, en la mayoría de los casos, la posibilidad de ajustar las características del producto, concepto, imagen y posicionamiento a las necesidades y preferencias del mercado, según los intereses particulares, en el marketing social tienen menos flexibilidad para darles forma y ofertarlos a los consumidores. El problema se ve aumentado por el hecho de que la mayor parte de los programas de marketing social tienen como objetivo el cambio de actitudes en el público al que se dirigen, es decir, que la aceptación de los "productos" que promovemos requiere un cambio de actitudes en nuestro segmento meta" Miquel et al., 1990: 99).

En este sentido, el marketing social pretende adecuar la demanda a la oferta, y no adecuar la oferta a la demanda, caso del marketing comercial. Por ende, las barreras y dificultades con las que el marketing social se enfrenta son mayores que las que el marketing comercial tiene que superar (Miquel et al., 1990: 99-100). El marketing social se basa más en el concepto de Venta que en el de Marketing (Miquel et al., 1990: 100).

El prisma que prima al concepto de Cambio de Comportamiento en el sistema teórico y conceptual del marketing social y que le otorga un status propio es empleado por algunos autores para establecer los criterios de segmentación pertinentes para los programas de marketing social.

Dado que el marketing social pretende adecuar la demanda a la oferta, y no la oferta a la demanda, y dado que sus programas se dirigen a mercados 


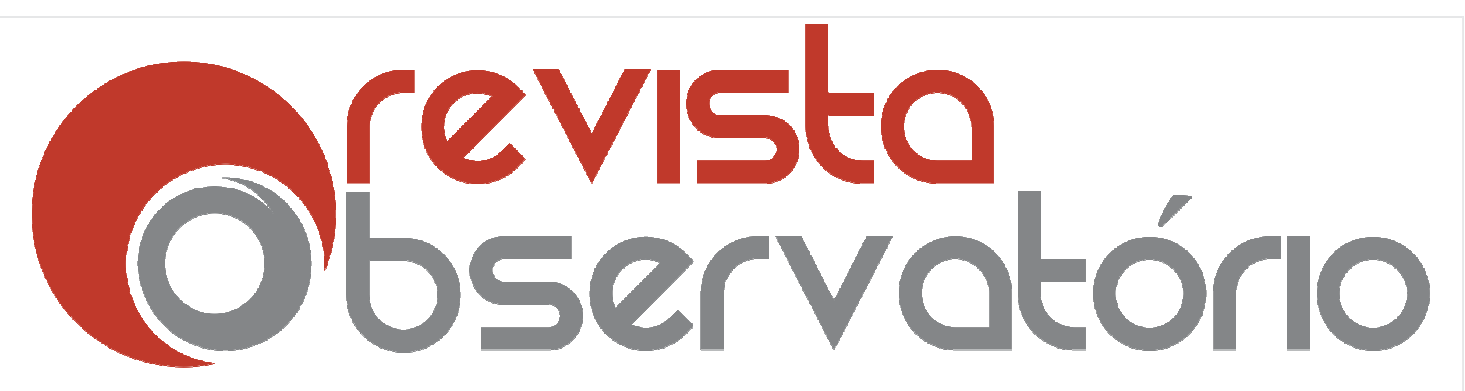

DOI: http://dx.doi.org/10.20873/uft.2447-4266.2018v4n1p437

meta de demanda negativa, los criterios base de segmentación de mercados más apropiados para idear programas de marketing social son los relacionados con los modelos de cambio de comportamiento.

Según Miquel y Moliner, tanto en el marketing comercial como en el marketing social son operativos los criterios subjetivos (generales y específicos) de segmentación. En el marketing social, además, "desde el punto de vista teórico, para elegir una variable de segmentación específica es necesario basarse en un modelo de comportamiento que relacione la causa social con las características propias del adoptante objetivo" (Miquel et al., 1996: 84-85).

\section{Conclusiones}

I. Respecto a las características de las crisis y de la comunicación institucional en contextos de crisis, exponemos el siguiente cuadro, en el que se da cuenta de la índole plural de las características de las crisis, si bien se remiten, por lo general, a la noción de tiempo y a la de afectación, mientras que las propiedades de la comunicación institucional son más homogéneas:

\begin{tabular}{|c|c|}
\hline Crisis & Comunicación institucional en crisis \\
\hline \multicolumn{2}{|r|}{ Características } \\
\hline $\begin{array}{l}\text { Puede afectar a cualquier } \\
\text { organización. }\end{array}$ & Busca hacerse con el control de la información. \\
\hline Cambio repentino. & $\begin{array}{l}\text { Objetivo de establecer relaciones de calidad } \\
\text { con sus públicos. }\end{array}$ \\
\hline $\begin{array}{l}\text { Daña la imagen, la } \\
\text { credibilidad y pone en } \\
\text { riesgo el futuro de la }\end{array}$ & $\begin{array}{l}\text { Búsqueda de eficacia en la gestión de } \\
\text { mensajes. }\end{array}$ \\
\hline
\end{tabular}




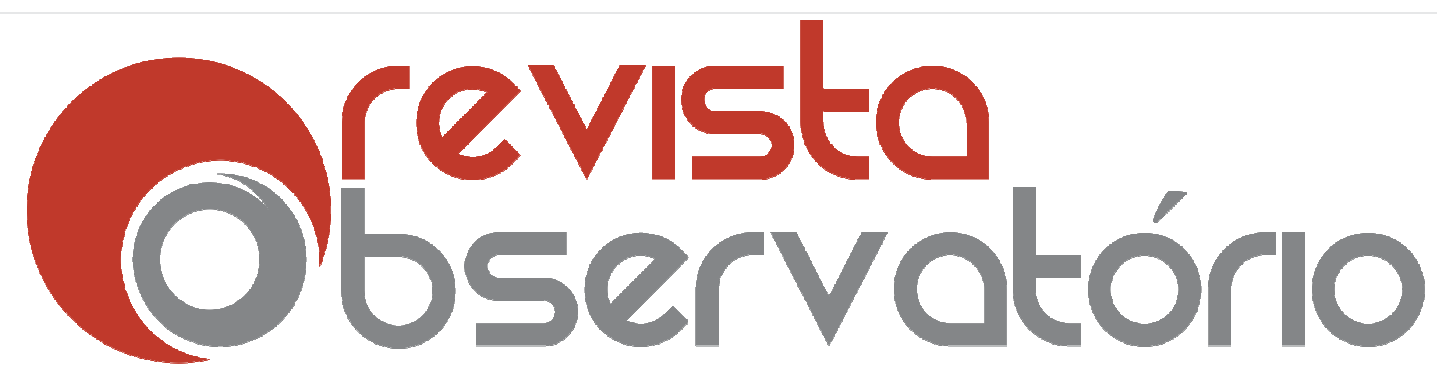

ISSN n² 2447-4266

Vol. 4, n. 1, Janeiro-Março. 2018

DOI: http://dx.doi.org/10.20873/uft.2447-4266.2018v4n1p437

\begin{tabular}{|c|c|}
\hline $\begin{array}{c}\text { organización. } \\
\text { públicos. }\end{array}$ & $\begin{array}{r}\text { Establecimiento de relaciones informativas } \\
\text { externas e internas. }\end{array}$ \\
\hline $\begin{array}{c}\text { Implicación de los medios } \\
\text { de comunicación. }\end{array}$ & $\begin{array}{c}\text { Busca generar notoriedad y difundir una } \\
\text { imagen pública adecuada a sus fines. }\end{array}$ \\
\hline $\begin{array}{c}\text { Interés de los poderes } \\
\text { públicos. }\end{array}$ & $\begin{array}{r}\text { Tiene el objeto de construir la identidad de la } \\
\text { organión. }\end{array}$ \\
\hline $\begin{array}{c}\text { Generan una situación de } \\
\text { objetivos planificados. }\end{array}$ \\
\hline $\begin{array}{c}\text { Sensación de pérdida de } \\
\text { control. }\end{array}$ \\
\hline $\begin{array}{c}\text { Los acontecimientos } \\
\text { suceden con rapidez. }\end{array}$
\end{tabular}

Fuente: elaboración propia, 2017.

II. La gestión de la comunicación institucional supone la gestión de actos de habla que constituyen discursos multisígnicos y que generan efectos cognitivos, emotivos y conductuales. Todo acto comunicativo tiene tres dimensiones que se realizan al unísono: dice algo (aspecto fonético, gramatical y rético -sentido y referencia-), hace algo al decir algo (por ejemplo, mandar, recomendar, desear, etc.) y produce unos efectos determinados en los sentimientos, pensamientos y acciones del receptor. Todo existente significa, y los individuos están contextualizados semánticamente en el hábitat cultural, 


\section{Observisto}

ISSN n² 2447-4266

Vol. 4, n. 1, Janeiro-Março. 2018

DOI: http://dx.doi.org/10.20873/uft.2447-4266.2018v4n1p437

atravesados por tramas de significación. Existen tres clases de signos considerando su naturaleza: cualisignos, sinsignos y legisignos, "todo comunica" y "todas las acciones y comportamientos de una organización tienen una dimensión comunicativa, es decir, hablan de la entidad". Esta visión holístico-comunicativa y multisígnica entronca con las lógicas culturales imperantes en las sociedades de la información y con la concepción de Verón con relación a la semiosis, por la que los signos instituyen el sentido de la realidad articulándose en discursos. Desde el punto de vista de la medición de los efectos comunicativos generados por las organizaciones, y en consonancia con los tres efectos sígnicos discernidos por Peirce, los efectos comunicativos de los signos son: cognitivos, emotivos y conductuales. Los signos contienen distintas informaciones e implican distintos mensajes que se comunican por distintos canales.

III. La comunicación corporativa se dirige a conseguir la misión de la organización. Mientras la comunicación comercial (comunicación de marketing) pretende conseguir un comportamiento de compra en el público objetivo consumidor-cliente, las relaciones públicas (comunicación institucional) pretenden conseguir en el público objetivo comercial y en el resto de públicos clave de la organización un comportamiento de apoyo a todas las actividades de la organización como tal (incluida la comercial). Estas estrategias de comunicación se conforman mediante dos elementos: emisión discursiva e introyección discursiva. La comunicación corporativa supone el uso del poder simbólico e instaura y fortalece relaciones de poder. Las fuerzas que se activan comunicativamente aplican estrategias que las organizaciones utilizan a fin de conseguir sus objetivos. Los discursos suponen prácticas discursivas. Los discursos y las prácticas que los sostienen y crean (emisoras e interiorizadoras) se encadenan en sucesivas capas de emisión-recepción-emisión. Las prácticas 


\section{Observisto}

ISSN n² 2447-4266

Vol. 4, n. 1, Janeiro-Março. 2018

DOI: http://dx.doi.org/10.20873/uft.2447-4266.2018v4n1p437

discursivas implican producción de discursos y conductas interiorizadoras de contenidos discursivos producidos, de modo que los discursos engloban prácticas productoras y prácticas receptoras. La comunicación en su aspecto relacional es un modo de poder. El poder simbólico envuelve a las otras formas de poder. La comunicación persuasiva es la "manipulación de signos con la intención de desatar una determinada conducta en la persona a la que nos dirigimos". La comunicación estratégica consiste en la gestión de la comunicación persuasiva para obtener objetivos.

IV. En los contextos de crisis las instituciones ven especialmente comprometida su imagen y, por tanto, la actitud de apoyo de los públicos estratégicos hacia ellas. El marketing social contempla una segmentación que se refiere a contextos sociales en los que los públicos objetivo no están predispuestos a practicar comportamientos que se pretende que realicen. Esta segmentación se adecua a modelos de cambio de comportamiento contrastados y atiende a las distintas problemáticas actitudinales de los públicos estratégicos, según niveles de intensidad de la actitud de los públicos estratégicos hacia la organización. La segmentación mediante mapa de públicos, comprendiendo que en el contexto de crisis institucional las actitudes hacia la organización cambian o, al menos, son más susceptibles de cambiar que en contextos estables, se torna especialmente útil para calibrar las acciones comunicativas adecuadas para cada público objetivo envuelto en la situación.

V. Hablar de comunicación institucional de crisis implica hacerlo sobre comunicación estratégica, cuyo planteamiento tiene como meta alcanzar una serie de objetivos previamente planificados. Las situaciones de crisis suponen momentos altamente delicados y que afecta a la integridad y estabilidad de las instituciones. En consecuencia, se expone la siguiente definición teórica, que afirma que la comunicación institucional en situaciones de crisis es: 


\section{Obvervatório}

ISSN n² 2447-4266

Vol. 4, n. 1, Janeiro-Março. 2018

DOI: http://dx.doi.org/10.20873/uft.2447-4266.2018v4n1p437

Las acciones de comunicación corporativa en contextos inestables y de fractura del acontecer, basadas en fundamentaciones estratégicas ad hoc, que suceden en situaciones imprevistas y que ponen en peligro la estabilidad, credibilidad, existencia e imagen de una institución (ya sea organización lucrativa o no lucrativa). Estos contextos de crisis suponen momentos altamente delicados y afectan a la integridad y estabilidad de las instituciones. Estas situaciones comprometen especialmente la imagen de la institución ante sus públicos objetivo y el apoyo estratégico que brindan a la institución. Las situaciones de crisis generan un problema urgente que precisa de una atención inmediata. La institución debe establecer relaciones informativas de calidad con todos sus públicos internos y externos mediante una gestión de signos, mensajes, discursos y sentidos adecuada a las actitudes que se van formando en los públicos durante el decurso de la crisis.

\section{Referencias}

ANDRÉU, J.: Las técnicas del análisis de contenido: una revisión actualizada [en línea], http://bit.ly/19kKyGH (consulta: 7-11-2014). 1998.

ARCEO, J. L: Estrategias de relaciones públicas. Metodologías. Madrid: ICIE, 1999.

ATENCIA, P: Peirce y la teoría de los signos. [En línea], http://bit.ly/2npNPgJ, (consulta: 1-5-2012), 2003.

AUSTIN, J.L: Cómo hacer cosas con palabras. Barcelona: Paidós, 1982.

BELTRÁN, L. R: Adiós a Aristóteles: la comunicación horizontal, en Walzer, Alejandra, García Marcial y Rodríguez, Juan Carlos: Comunicación alternativa, ciudadanía y cultura. Foro Universitario de Comunicación. Madrid, 2007.

BERGANZA, M. R., \& RUIZ, J. A: Investigar en comunicación: Guía

práctica de métodos y técnicas de investigación social en comunicación. Madrid: McGraw Hill, 2010.

BERGANZA, M. R., \& GARCÍA, M: El método científico aplicado a la investigación en comunicación (pp. 19). BERGANZA, M. R., \& RUIZ, J. (coord.): Investigar en 


\section{Observatório}

DOI: http://dx.doi.org/10.20873/uft.2447-4266.2018v4n1p437

comunicación: Guía práctica de métodos y técnicas de investigación social en comunicación. Madrid: McGraw Hill, 2010.

BLOOMFIELD, L: El lenguaje. México: Universidad Autónoma de México, 1968.

BRAUDILLARD, J: Perspectivas sobre comunicación y sociedad. Valencia, uv, 2004.

BUENFIL, R: Foucault y la analítica del discurso. [En línea], http://bit.ly/2ntcCki. Topos y tropos, no 2, pp. 1-12, 1996, (consulta: 24-122011), 1996.

BURGUEÑO, J. M: Comunicación institucional para periodistas. Manual práctico de comunicación y relaciones públicas. Barcelona: Editorial UOC, 2014.

CAPRIOTTI, P: Branding corporativo. Santiago de Chile: Libros de la Empresa, 2009.

CASTILLO, A: Introducción a las Relaciones Públicas. [En línea], http://bit.ly/2moPL7X (consulta: 5-03-2015), 2010.

CERVERA, A. L: Comunicación total. Madrid: ESIC, 2008.

COSTA, J: La comunicación en acción. Informe sobre la nueva cultura de la gestión. Barcelona: Paidós, 1999.

COSTA, J: El Dircom hoy. Barcelona: Costa Punto Com Editor, 2009.

CUDICIO, C: Cómo comprender la PNL. Introducción a la Programación Neurolingüística. Barcelona: Granica, 1996.

FITA, J: Comunicación en programas de crisis. Barcelona: Gestión 2000, 1999.

FOUCAULT, M: Vigilar y castigar. Nacimiento de la prisión. Buenos Aires:

Siglo XXI, 2005.

GADAMER, H: Verdad y método. : Salamanca: Ediciones Sígueme, 2001.

GALLARDO: L: (ed.): Nuevos movimientos sociales y comunicación corporativa: la revolución de la acción. [En línea] http://perio.unlp.edu.ar/iicom/sites/perio.unlp.edu.ar.iicom/files/nuevos_movimi entos_sociales_y_comunicacion_corporativa.pdf, La Plata: EDULP (consulta: 1304-2016), 2014.

GARCIA, S: La comunicación en momentos de crisis: los gabinetes de comunicación municipales en España. ISLAS, O., \& HERNÁNDEZ, G. (coord.): Investigando la Comunicación en Crisis (pp. 123). [En línea], http://bit.ly/1MARjCk, México: Razón y Palabra (consulta: 5-03-2015), 2013. GEERTZ, C: La interpretación de las culturas. Barcelona: Gedisa, 1992. 


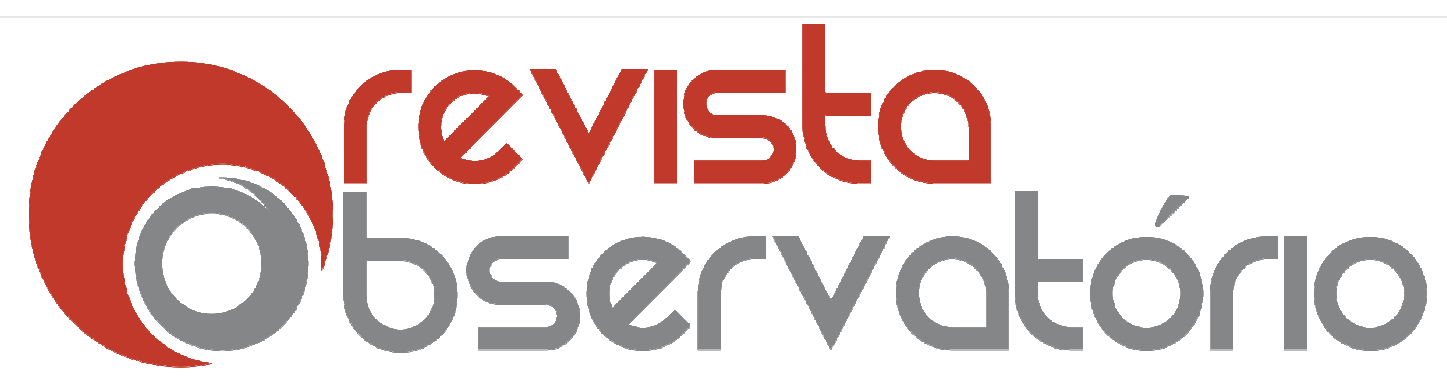

ISSN n² 2447-4266

Vol. 4, n. 1, Janeiro-Março. 2018

DOI: http://dx.doi.org/10.20873/uft.2447-4266.2018v4n1p437

GIL, P: El tratamiento informativo de la crisis y su gestión: Cómo salvar la situación. ISLAS, O., \& HERNÁNDEZ, G. (coord.): Investigando la Comunicación en Crisis (pp. 28). [En línea] http://bit.ly/1MARjCk, México: Razón y Palabra (consulta: 12-04-2015), 2013.

GONZÁLEZ HERRERO, A: Marketing preventivo: la comunicación de crisis de la empresa. Barcelona: Bosch, S.A., 1998.

GRUNIG, J., HUNT, T: Dirección de relaciones públicas. Barcelona: Gestión 2000, 2000.

HEIDEGGER, M: Ser y Tiempo. Chile: Universitaria, 1997.

HERRANZ, J.M: La comunicación dentro de las organizaciones no lucrativas. La construcción de la confianza con los ciudadanos. [En línea], http://bit.ly/2o1llUF. Razón y Palabra n 58, 2007.

HJELMSLEV, L. (1971): Prolegómenos a una teoría del lenguaje. Madrid: Gredos.

HUME, D: Tratado Sobre la Naturaleza Humana. Buenos Aires: Ágora, 1959.

KLAUS, A: Una epistemología histórica de la pedagogía. El trabajo de Olga Lucía Zuluaga. Revista de Pedagogía, Vol. 23, N.º 68, pp.361-385, 2002.

LA PORTE, J: Organizaciones religiosas: comunicar lo invisible. LOSADA, J.

C. (coord.): Gestión de la comunicación en las organizaciones (pp. 491). Barcelona: Editorial Ariel, 2010.

$L E A L, A$ : El marketing social en España: situación actual y estrategias para su desarrollo. Revista Internacional de Marketing Público y No Lucrativo, Vol. 1, N. ${ }^{\circ}$ 1, pp. 32-52, 2004.

LEWANDOWSKI, T: Diccionario de lingüística. Madrid. Cátedra, 1982.

LUCERGA, $M^{a}$ J: "Gregory Bateson: lectura en clave semiótica de una aventura epistemológica del siglo XX" [En línea], http://bit.ly/2mnAdBd, Tonos Digital: Revista Electrónica de Estudios Filológicos, $n^{\circ}$ 5, (consulta: 10-52012), 2003.

LUECKE, R: Gestión de crisis convertirlas en oportunidades. Barcelona: Ediciones Deusto, 2005.

MAGARIÑOS, J: El signo. Las fuentes teóricas de la Semiología. Saussure, Peirce, Morris, Buenos Aires: Hachette, 1983.

MARTÍN, F: Comunicación empresarial e institucional. Madrid: Editorial Universitas, S.A, 2006. 


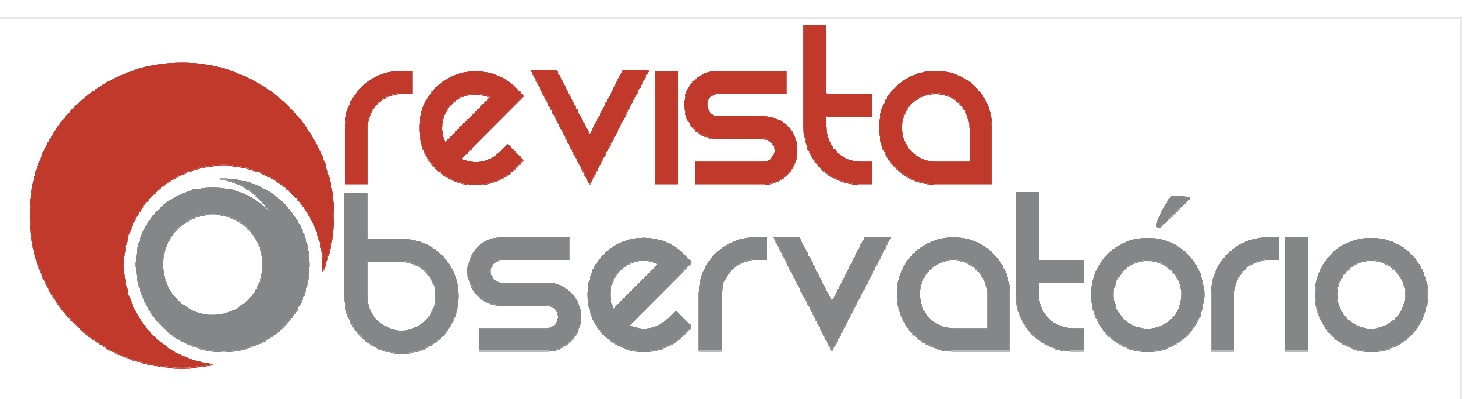

MATILLA, K: Los modelos de la planificación estratégica en la Teoría de las Relaciones Públicas. Barcelona, UOC, 2008.

MATTELART, A., MATTELART, M: Historia de las teorías de la comunicación. Barcelona: Paidós, 1995.

MINGUEZ, N: Un marco conceptual para la comunicación corporativa. [En línea], http://bit.ly/2nH0qQl. Zer, no 8. Consulta: 10 de octubre del 2012, 2000. MIQUEL, S., DÍAZ, R: Los estilos de vida como alternativa de segmentación en el marketing social. Revista de Economía y Empresa, vol. 10, N²6, pp. 95105. G, 1990.

MIQUEL, S., MOLINER, M. A: La segmentación del mercado en el marketing social y el paradigma actitud-comportamiento. Revista Europea de Dirección y Economía de la Empresa, Vol. 5, N.2 2, pp. 83-96, 1996.

ORTIZ, M: Las Fronteras entre poder, estado y medios de comunicación masiva desde la teoría crítica. Estudios Fronterizos, 7, 9-31, 2006.

PEIRCE, C: La ciencia de la Semiótica. Buenos Aires: Nueva Visión, 1986.

PÉREZ, J. A: Filosofía y crítica de la cultura. Madrid: Trotta, 1995.

PINILLOS, J. L: "La significación desde el punto de vista psicológico". Revista Española de Lingüística, no 1, pp. 97-118, 1971.

PIÑUEL, J. L: Teoría de la comunicación y gestión de las organizaciones. Madrid: Editorial Síntesis S.A., 1997.

PULGAR, L: Comunicación de empresa en entornos turbulentos. Madrid: ESIC, 1999.

REDONDO, I: La comunicación en Charles S. Peirce: análisis de sus textos fundamentales. [En línea], http://bit.ly/2npLOMP. Universidad de Navarra, Tesis de Doctorado, 2006.

ROMO, Ma E., LÓPEZ, I., LÓPEZ, D: “¿Eres visual, auditivo o kinestésico? Estilos de aprendizaje desde el modelo de la Programación Neurolingüística (PNL)". Revista Iberoamericana de Educación, vol. 38, nº. 2, pp. 1-10, 2006.

SALAS, M., I: Estrategias de comunicación. Barcelona: Ariel, 2001.

SANTILLÁN, V., ORTIZ, A: La noción de poder desde Foucault. Una perspectiva educomunicacional. Perspectivas de la Comunicación, vol. 4, $n^{\circ} 1$, pp. 80-91, 2011. 


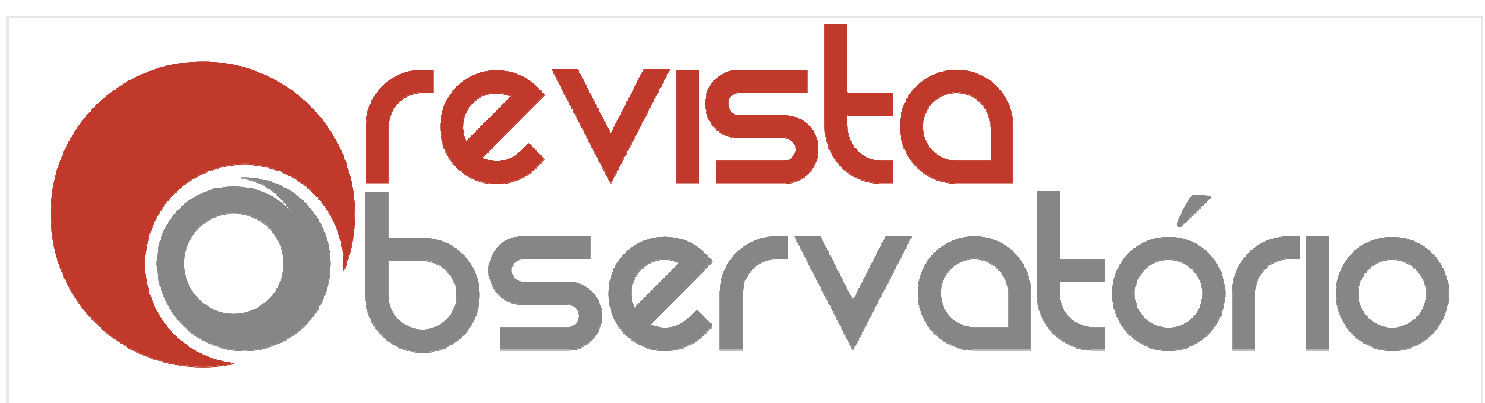

ISSN n² 2447-4266

Vol. 4, n. 1, Janeiro-Março. 2018

DOI: http://dx.doi.org/10.20873/uft.2447-4266.2018v4n1p437

SAURA, P: La gestión y la comunicación de crisis en el sector de la alimentación y de las bebidas. Madrid: Universidad Pontificia de Comillas, 2005.

SAUSSURE, F: Curso de Lingüística General. Buenos Aires: Losada, 1945.

SOTELO, C: Introducción a la comunicación institucional. Barcelona: Editorial Ariel, S. A., 2008.

THOMPSON, J: Los media y la modernidad. Una teoría de los medios de comunicación. Barcelona: Paidós, 1997.

VALLES, M. S: Técnicas cualitativas de investigación social. Madrid: Síntesis, 2000.

VAN RIEL, C: La comunicación corporativa. Madrid: Prentice-Hall, 1997.

VÉLIZ, F: Cambio de mirada en las organizaciones: comunicación en $\mathbf{3 6 0}$ grados. Chasqui, n 3, pp. 62-65, 2006.

VERA, $\mathrm{H}$ : Diferencias teóricas y prácticas entre información y comunicación, Re-Presentaciones, Periodismo, Comunicación y Sociedad, n¹, pp. 9- 35, 2006.

VERÓN, E.: La semiosis social. Fragmentos de una teoría de la discursividad. Barcelona: Gedisa, 1993.

VIDAL, F., \& HERNÁNDEZ, H. G: Medios y crisis: Una nueva visión sobre la estrategia de respuesta (pp. 146). ISLAS, O., \& HERNÁNDEZ, G. (coord.): Investigando la Comunicación en Crisis. [En línea], http://bit.ly/1MARjCk, México: Razón y Palabra (consulta: 5-03-2015), 2013.

VILLAFAÑE, J. (2004). La buena reputación. Claves del valor intangible de las empresas. Madrid: Editorial Pirámide.

VILLAFAÑE, J: La gestión profesional de la imagen corporativa. Madrid: Editorial Pirámide, 2008.

WILCOX, D. L., CAMERON, G. T. \& XIFRA, J: Relaciones Públicas estrategias y tácticas. Madrid: Pearson Educación S.A., 2009.

WIMMER, R. D., DOMINICK, J. R.: La investigación científica de los medios de comunicación. Barcelona: Bosch, 1996. 